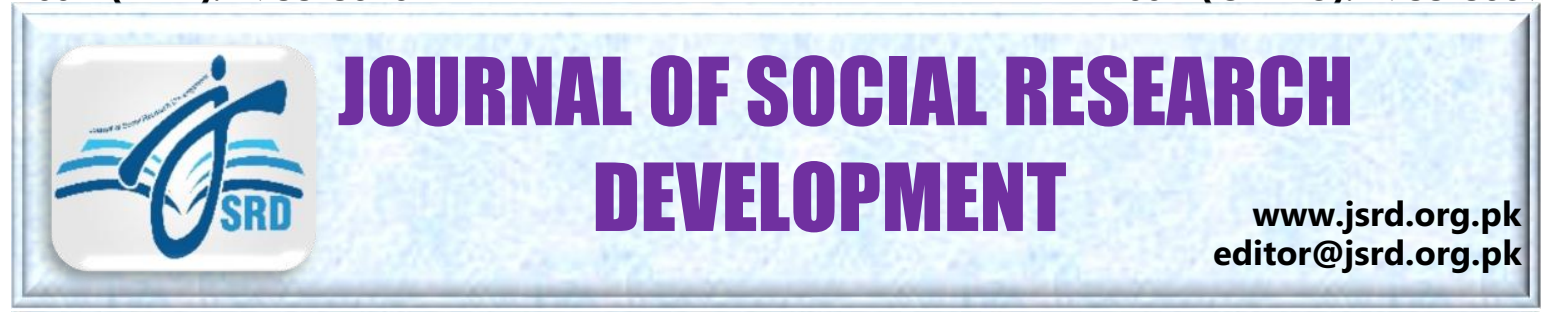

\title{
THE IMPACT OF MODERATE INTENSITY AEROBIC EXERCISES UPON BODY COMPOSITION OF COLLEGE GIRLS
}

Fouzia Nawaz ${ }^{1}$, Muhammad Safdar Luqman ${ }^{2}$ \& Muhammad Asghar Khan ${ }^{3}$

${ }^{1}$ Department of Sports Sciences and Physical Education, Gomal University, Dera Ismail Khan ${ }^{2}$ Instructor Physical Education, Elementary \& Secondary Education Department KP, Pakistan ${ }^{3}$ Instructor Physical Education, Elementary \& Secondary education Department KP, Pakistan

\begin{tabular}{l|l}
\hline KEYWORDS & \multicolumn{1}{l}{ ABSTRACT } \\
\hline Moderate & This experimental study aimed to investigate impact of moderate intensity \\
Exercity Aerobic & aerobic exercises upon Body Composition of college girls. The experimental \\
Composition & $\begin{array}{l}\text { research method was adopted for current study with longitudinal approach } \\
\text { i.e., pre-test and post-test. 40 participants were taken as a population and } \\
\text { were randomly divided into two groups, experimental and Control group. } \\
\text { Eight-week moderate intensity aerobic exercises were given to experimental } \\
\text { group. After the completion of eight-week exercise protocol the data of } \\
\text { Body composition, data of pretest and posttest was recorded and analyzed } \\
\text { using paired sample t test and ANOVA to check the difference between the } \\
\text { body composition score of girls in pre-test and post-test. It was found that } \\
\text { there is significant impact of Moderate intensity aerobic exercises upon the } \\
\text { post-test of experimental group. The results provides significant information } \\
\text { in deciding the relationships among the research variables in order to reach } \\
\text { the conclusion. }\end{array}$ \\
\hline Corresponding Author & Muhammad Safdar Luqman, Email: safdarkhan821@gmail.com \\
\hline DOI & https://doi.org/10.53664/JSRD/02-01-2021-03-29-40 \\
\hline
\end{tabular}

\section{INTRODUCTION}

There is an adverse association in-between Body Mass Index (BMI) and walk (Bahamonde, Witt \& Mikesky 2009). BMI is a key or content and index, generally used to classify severity of fats (Shah \& Braverman, 2012). Walking and running are considered the most important muscle groups of body and is prospectively desirable to running (Ford \& Swaine 2011). In addition to, in person it was observed walking play a major role in reduction of fats from the body (Hardman, 2001). Accumulated short but abrupt walking throughout the day can lead to positive changes in body composition in adults (Asikainenet al., 2006). Reid et al., (1995) The impact of exercise is also very much helpful to maintain a good level of body weight but at the same time it is very important to study that whether impact of exercise upon the fat mass is in any relationship with growth of body weight. The author further stated that the impact of the exercise upon the fat mass was found to be positive, since it 
helped to maintain a required level of fat mass and helped to maintain good body weight by maintain the fat mass.

The relationship between fat mass and lean body mass due to moderate intensity aerobic exercises was found to have positive impact upon body mass index. The study was favored with two techniques to find out the impact of moderate intensity aerobic exercises upon the body mass index by investigating impact of exercise on any component of the moody, as in presence case the fat mass is used. According to Hill, Drougas and Peters (1993) of diet composition can play a major role in maintenance of the health by decreasing factor of obesity. By performing exercise likes moderate intensity aerobic exercises the energy expenditure is introduced to the body mechanism an in result all extra energy is conserved by performing different activities and no fat mass is built within the body. Due to exercise the weight loss occurs and in result of it the negative energy is wasted. In weight loss the impact of moderate intensity aerobic exercises is of very importance as compared with the diet plans with less efficiency.

Once the body waste fat is reduced it is very important that the proper mechanism should be attained in order to maintain this new weight. Studies show that exercises help people in weight management irrespective of change in diet. Due to exercise fat mass decreases while lean mass is preserved. Higher proportions of lean body mass may be lost rather than overall fat due to exercise response. It has been found that VAT (viral adipose tissue) responds more significantly to exercise as compared to other depots. The reason for this significant respond is high level of adrenergic activation in VAT (Cook et al., 2008). Body composition can be assed with help of skinfold measurement and skinfold measurement is related to body fitness. One can have an idea about lean tissue and body fat by measuring skinfold of different body parts. Different methods proposed by health expert to assess the composition of body but not all method can be practiced easily skinfold measurement is a method of minimal cost (Clark at al., 2008).

But it must be noted that skinfold measurement cannot accurately assess body composition after exercise for the reason that after exercise skin becomes thick than normal because water in subcutaneous tissue causes peripheral vasodilation (Golding et al., 1998). As per to Chen et al (2014) Increase in the mid arm circumference by one inch shown a reduced effect of death due to any of these diseases. Among the population the peoples with a low level of BMI were found to be associated with allow level disease risk and mortality rate. It was stated at the end that the hypothesis was a true one and there is a close impact of the mid arm circumference upon mortality rate in lean Asian. BMI is mostly used for assessing the obesity of a person, yet it has disadvantages like for reflecting body frame size, fat free mass and relative leg length. And also, for BMI two measurements i.e., weight and height are required. 
It has been found that in some cases weight or height of a person cannot be measured so screen the obesity in that case MAC is used to screen the obesity. In the present study the researcher intended to conduct research study under title Impact of Moderate Intensity Aerobic Exercises upon Body Composition of College Girls. The main objectives of study were a) to compare the Body Composition in pretest and posttest of Experimental group and control group. b) to analysis impact of Moderate Intensity Aerobic Exercise upon the Body Composition of the college girls.

\section{LITERATURE REVIEW}

For the purpose to improve health there are some benefits of the aerobic exercise. Aerobic exercise improves heart muscles and efficiency of the heart. According to Moyer (2012) aerobic exercise helps in reducing the RHR which is the signal of physical fitness. The red blood cells work is that to convey $\mathrm{O} 2$ to every tissue of body, aerobic exercise improves the red blood cells. Red blood cells formed bone marrow which is very imported for the purpose of aerobic exercise (Swain \& Franklin, 2006). Cornelissen et al. (2010) stated that aerobic exercises improve muscles tone, increased number of capillaries and helped in circulation of blood which remove the waste material from the body, which is the cause of fatigue. Stiegler and Cunliffe (2006) show that obesity is a common problem in our world since past few years. Two main components are used to hinder obesity and to maintain fat free mass to a good level. They are a proper diet for maintain fat free mass and moderate intensity aerobic exercises. A good diet will help to maintain a good level of fat free mass and reduction in the level of fat mass.

The moderate intensity aerobic exercises are very effective in terms to maintain fat free mass by losing a huge level of fat mass in term of energy expenditure while performing different activities. Intensity of exercise greatly affect substrate metabolism. After exercise the secretion of hormones which cause the breakdown of fats increases. Therefore, post exercise energy expenditure and oxidation of fat increases. Studies show that exercises help the people in weight management irrespective of change in diet. Due to exercise fat mass decreases while lean mass is preserved. Higher proportions of lean body mass may be lost rather than overall fat due to exercise response. It has been found that VAT (viral adipose tissue) responds more significantly to exercise as compared to other depots. The reason for this significant respond is the high level of adrenergic activation in VAT (Cook et al., 2008). Through the investigation of various studies performed in the past it has been evaluated that the exercise plays an important role in the maintenance of the weight, controlling obesity and it is also found that the impact of the diet is also critical in such maintenance.

The exercise plays an important role in $\mathrm{b}$ prevention of obesity be reducing the amount of fat mass in the body and by conserving the amount of lean body mass (Willoughby, Hewlings, \& Kalman, 2018; Leijssen \& Saris, 2002). According to Prabhakaran et al (1999) 
there is significant impact of the exercise protocol upon the fat percentage reduction of the participants. The cholesterol level of the participants of the exercise protocol was also reduced to a low level. The result of the study stated that there was a huge difference between the baseline values of fat percentage, cholesterol and fat mass to the final values obtained after the application of protocol for the participants. The result of the study stated that there exists a huge relationship between reduction of the fat percentage, body mass and cholesterol level of the obese, healthy or sedentary life style containing women to the moderate intensity aerobic exercises protocol. According to McTiernan et al (2007) increase in the level of the exercise the decrease in the fat percentage of the population was observed.

According to Narayani \& Sudhan (2010) there is a significant impact of moderate intensity aerobic exercises upon the fat percentage reduction, cholesterol level reduction and body fat reduction as well. Bahamondeet al (2009) carried out their research on measurement of skinfold after exercise. They were determining that if acute moderate exercise can affect the results of skinfold thickness after exercise. In their study 30 subjects were divided in three groups: control, resistance exercise, and aerobic exercise. Skinfold measurement was recorded before exercise and then the aerobic group exercised for 25 minutes and two sets of 12 different exercises were performed in a circuit fashion for the lower and upper body parts. Thus, again, skinfold measurement was recorded and ANCOVA was used to determine the pre-test and post-post differences. And it was found that there was not much difference between the results the value of $p$ was $p<.05$. According to Chen et al (2014) Increase in mid arm circumference by one inch shown a reduced effect of death due to any of these diseases.

Among the population the peoples with a low level of BMI were found to be associated with allow level disease risk and mortality rate. It was stated at the end that the hypothesis was a true one and there is a close impact of mid arm circumference upon the mortality rate in lean Asian. Although BMI is mostly used for assessing the obesity of a person, yet it has disadvantages like for reflecting body frame size, fat free mass and relative leg length. And also for BMI two measurements i.e. weight and height are required. It has been found that in some cases weight or height of a person cannot be measured so screen the obesity in that case MAC is used to screen the obesity. Nayanaet al (2015) evaluated alternate anthropometric index for the obese people with T2D and metabolic syndrome, 207 T2D patients and 101 metabolic syndrome subjects were selected for the study. Therefore, the anthropometric parameters like the MAC, waist circumference and BMI were measured. Independent T-test was performed by them to compare biochemical and anthropometric parameters.

MAC was correlated with biochemical parameters and it was found that MAC is a useful alternate index for obesity and is reliable to measure the obesity in people of South India. It was also observed by them that MAC was higher in metabolic syndrome patients as 
Nawaz, Luqman \& Khan... The Impact of Moderate

compared to patients with T2D hence MAC can predict T2D in people before its onset (Nayanaet al., 2015).

\section{RESEARCH METHODS}

This experimental study aimed to assess impact of moderate intensity aerobic exercises upon Body Composition of college girls. Experimental research method was adopted for the current study with longitudinal approach i.e., pre-test and post-test. 40 participants were taken as a population and were randomly divided into two groups, experimental and Control group. Eight-week moderate intensity aerobic exercises were given to experimental group. After the completion of eight-week exercise protocol data of Body composition, the data of pretest and posttest was recorded and analyzed using paired sample $t$ test and ANOVA to check the difference between the body composition score of girls in pre-test and post-test. It was found that there is significant impact of Moderate intensity aerobic exercises upon the post-test of experimental group.

\section{DATA ANALYSES}

The results of current study as the outcomes of the statistical analysis used for chasing the research questions have been offered in this section in order to understand the main theme and desired outcomes.

Table 1 Category-wise Frequencies and Percentages

\begin{tabular}{ccc}
\hline Category & $\mathrm{F}$ & $\%$ \\
\hline Experimental Group (Moderate Intensity Aerobic Exercises) & 20 & 50.0 \\
Control Group (Ordinary routine life) & 20 & 50.0 \\
\hline Total & 40 & 100.0 \\
\hline
\end{tabular}

Table 1 shows that total subjects in the experimental group (Moderate Intensity Aerobic Exercises) were 20 and percentage was $50 \%$ and total subjects in control group (Ordinary routine life) were 20 and percentage was $50 \%$.

Table 2 Descriptive of Experimental and Control Group in Body Composition

\begin{tabular}{lccc}
\hline & & Pretest & Posttest \\
\hline Measurements & $\mathrm{N}$ & Mean \pm SD & Mean \pm SD \\
Fat free mass/lean body mass $(\mathrm{kg})$ & 40 & $49.43 \pm 1.27$ & $49.13 \pm 1.28$ \\
Fat mass $(\mathrm{kg})$ & 40 & $23.46 \pm 1.26$ & $22.05 \pm 1.74$ \\
Fat percentage & 40 & $27.47 \pm 3.55$ & $25.96 \pm 3.87$ \\
Sum of skin fold measurements $(\mathrm{mm})$ & 40 & $70.45 \pm 5.63$ & $65.34 \pm 7.41$ \\
Mid-calf circumference $(\mathrm{cm})$ & 40 & $28.58 \pm 1.88$ & $27.02 \pm 2.20$ \\
Mid-Thigh Circumferences $(\mathrm{cm})$ & 40 & $50.97 \pm 1.93$ & $48.86 \pm 2.69$ \\
Mid Arm Circumferences $(\mathrm{cm})$ & 40 & $29.03 \pm 2.18$ & $27.93 \pm 2.34$ \\
Waist Hip Ratio & 40 & $.68 \pm .05$ & $.67 \pm .05$ \\
\hline Weight & 40 & $63.42 \pm 3.75$ & $61.30 \pm 4.38$ \\
\hline
\end{tabular}


Table 2 show descriptive of experimental and control group in RHR and body composition in pretest and posttest. Measurement of Fat free mass/lean body mass $(\mathrm{kg})$ was $49.43 \pm 1.27$ in pretest and $49.13 \pm 1.28$ in posttest. In the same way the measurement of Fat mass $(\mathrm{kg})$ was $23.46 \pm 1.26$ in pretest and $22.05 \pm 1.74$ in posttest. Similarly, the measurement of Fat percentage of 40 participants in pretest was $27.47 \pm 3.55$ and posttest was $25.96 \pm 3.87$. The Sum of skin fold measurements $(\mathrm{mm})$ of the participant in pretest was $70.45 \pm 5.63$ and in posttest was $65.34 \pm 7.41$. The Mid-calf circumference $(\mathrm{cm})$ of the participant in pretest was $28.58 \pm 1.88$ and in posttest was $27.02 \pm 2.20$. The Mid-Thigh Circumferences $(\mathrm{cm})$ of the participant in pretest was $50.97 \pm 1.93$ and in THE posttest was $48.86 \pm 2.69$. The Mid Arm Circumferences $(\mathrm{cm})$ of the participant in pretest was $29.03 \pm 2.18$ and in posttest was $27.93 \pm 2.34$. The Waist Hip Ratio of the participant in pretest was $.68 \pm .05$ and in posttest was $.67 \pm .05$. The Weight of the participant in pretest was $63.42 \pm 3.75$ and in posttest was $61.30 \pm 4.38$.

Table 3 Comparison of Body Composition in Pretest and Posttest of Experimental Group

\begin{tabular}{llllll}
\hline & & Pretest & Posttest & $\mathrm{t}$ & Sig. \\
\hline \multicolumn{1}{c}{ Measurements } & $\mathrm{N}$ & Mean \pm SD & Mean \pm SD & & \\
Fat free mass/lean body mass $(\mathrm{kg})$ & 20 & $49.23 \pm 1.35$ & $48.64 \pm 1.20$ & 5.983 & .000 \\
Fat mass $(\mathrm{kg})$ & 20 & $23.57 \pm 1.00$ & $20.76 \pm .732$ & 26.325 & .000 \\
Fat percentage & 20 & $27.43 \pm 3.58$ & $24.43 \pm 3.58$ & 127.859 & .000 \\
Sum of skin fold measurements (mm) & 20 & $70.59 \pm 3.77$ & $60.59 \pm 5.77$ & 1.750 & .006 \\
Mid-calf circumference $(\mathrm{cm})$ & 20 & $28.86 \pm 1.89$ & $25.86 \pm 1.89$ & 61.820 & .000 \\
Mid-Thigh Circumferences $(\mathrm{cm})$ & 20 & $51.01 \pm 1.94$ & $47.01 \pm 1.94$ & 71.109 & .000 \\
Mid Arm Circumferences $(\mathrm{cm})$ & 20 & $29.09 \pm 2.23$ & $27.09 \pm 2.23$ & 66.479 & .000 \\
Waist Hip Ratio & 20 & $.68 \pm .057$ & $.66 \pm .057$ & 13.784 & .000 \\
\hline Weight & 20 & $63.45 \pm 3.32$ & $59.05 \pm 3.28$ & 15.983 & .000 \\
\hline
\end{tabular}

Table 3 showing the treatment group difference between measurement before and after the treatment in 9 components of body composition, the data shows that significantly the pretest measurement of Fat free mass/lean body mass $(\mathrm{kg})(49.23 \pm 1.35)$, of experimental group was different from the posttest measurement of Fat free mass/lean body mass $(\mathrm{kg})$ $(48.64 \pm 1.20) \mathrm{t} 19=5.983, \mathrm{p}<.05$. Similarly, significantly pretest measurement of Fat mass (kg) $(23.57 \pm 1.00)$, of experimental group was different from the posttest measurement of Fat mass $(\mathrm{kg})(20.76 \pm .732) \mathrm{t} 19=26.325, \mathrm{p}<.05$. In the same way significantly the pretest measurement of Fat percentage $(27.43 \pm 3.58)$, of experimental group was different from the posttest measurement of Fat percentage $(24.43 \pm 3.58) \mathrm{t} 19=127.859, \mathrm{p}<.05$. In the same stance significantly the pretest measurement of Sum of skin fold measurements ( $\mathrm{mm})(70.59 \pm 3.77)$, of experimental group was different from the posttest measurement of Sum of skin fold measurements $(\mathrm{mm})(60.59 \pm 5.77) \mathrm{t} 19=1.750, \mathrm{p}<.05$. In the same way, significantly the pretest measurement of Mid-calf circumference $(\mathrm{cm})(28.86 \pm 1.89)$, of 
Nawaz, Luqman \& Khan... The Impact of Moderate

experimental group was different from posttest measurement of Mid-calf circumference (cm) $(25.86 \pm 1.89) \mathrm{t} 19=61.820, \mathrm{p}<.05$.

In the same way, significantly the pretest measurement of Mid-Thigh Circumferences $(\mathrm{cm})$ (51.01 \pm 1.94$)$, of experimental group was different from the posttest measurement of MidThigh Circumferences $(\mathrm{cm})(47.01 \pm 1.94) \mathrm{t} 19=71.109, \mathrm{p}<.05$. In the same way, significantly the pretest measurement of Mid Arm Circumferences $(\mathrm{cm})(29.09 \pm 2.23)$, of experimental group was different from the posttest measurement of Mid Arm Circumferences $(\mathrm{cm})$ $(27.09 \pm 2.23) \mathrm{t} 19=66.479, \mathrm{p}<.05$. Similarly, the data indicates that significantly the pretest measurement of Waist Hip Ratio (.68 \pm .057$)$, of experimental group was different from the posttest measurement of Waist Hip Ratio $(.66 \pm .057) t 19=13.784, p<.05$. In the same way, significantly the pretest measurement of weight $(63.45 \pm 3.32)$, of experimental group was different from the posttest measurement of weight $(59.05 \pm 3.28) \mathrm{t} 19=15.983, p<.05$. In respect of resting heart score of experimental groups in pretest and posttest the data indicate that the score of pretests of RHR $(76.35 \pm 3.85)$ and post of RHR $(71.55 \pm 3.45)$ were significantly different. The above table indicates that Moderate Intensity Aerobic exercise positively impact the nine selected components of body composition and resting heart rate of 20 college female students in experimental group.

Table 4 Comparison of Body Composition in Pretest and Posttest of Control Group

\begin{tabular}{lllll}
\hline \multicolumn{1}{c}{ Measurements } & $\begin{array}{l}\text { Experimental Group } \\
(\mathrm{N}=20)\end{array}$ & $\begin{array}{l}\text { Control Group } \\
(\mathrm{N}=20)\end{array}$ & $\mathrm{t}$ & Sig. \\
\hline Fat free mass/lean body mass $(\mathrm{kg})$ & Mean $\pm \mathrm{SD}$ & Mean $\pm \mathrm{SD}$ & & \\
Fat mass $(\mathrm{kg})$ & $48.64 \pm 1.20$ & $49.63 \pm 1.18$ & -2.625 & .012 \\
Fat percentage & $20.76 \pm .732$ & $23.34 \pm 1.4$ & -6.964 & .000 \\
Sum of skin fold measurements $(\mathrm{mm})$ & $24.43 \pm 3.58$ & $27.50 \pm 3.61$ & -2.698 & .010 \\
Mid-calf circumference $(\mathrm{cm})$ & $60.59 \pm 5.77$ & $70.10 \pm 5.63$ & -5.271 & .000 \\
Mid-Thigh Circumferences $(\mathrm{cm})$ & $25.86 \pm 1.89$ & $28.18 \pm 1.89$ & -3.888 & .000 \\
Mid Arm Circumferences $(\mathrm{cm})$ & $47.01 \pm 1.94$ & $50.71 \pm 1.97$ & -5.977 & .000 \\
Waist Hip Ratio & $27.09 \pm 2.23$ & $28.77 \pm 2.20$ & -2.396 & .022 \\
\hline Weight & $.66 \pm .057$ & $.68 \pm .058$ & -.984 & .331 \\
\hline $\mathrm{a}=0.05$ & $59.05 \pm 3.28$ & $63.55 \pm 4.24$ & -3.754 & .001 \\
\hline
\end{tabular}

Table 4.8 showing the control group difference between the measurement before and after the treatment in 9 components of body composition and resting heart rate, the data shows that significantly the pretest measurement of Fat free mass/lean body mass $(\mathrm{kg})$ $(49.78 \pm 1.33)$, of control group was not different from posttest measurement of Fat free mass/lean body mass $(\mathrm{kg})(49.63 \pm 1.18) \mathrm{t} 19=3.693, \mathrm{p}>.05$. Similarly, significantly pretest measurement of Fat mass $(\mathrm{kg})(23.35 \pm 1.49)$, of control group was not different from the posttest measurement of Fat mass $(\mathrm{kg})(23.34 \pm 1.4) \mathrm{t} 19=.387, \mathrm{p}>.05$. In the same way 
significantly pretest measurement of Fat percentage (27.51 \pm 3.61$)$, of control group was not different from the posttest measurement of Fat percentage $(27.50 \pm 3.61) \mathrm{t} 19=3.000$, $p>.05$. In the same stance significantly the pretest measurement of Sum of skin fold measurements $(\mathrm{mm})(70.33 \pm 5.64)$, of control group was not different from the posttest measurement of Sum of skin fold measurements $(\mathrm{mm})(70.10 \pm 5.63) \mathrm{t} 19=13.397, \mathrm{p}>.05$. In same way, significantly pretest measurement of Mid-calf circumference $(\mathrm{cm})(28.42 \pm$ 1.86), control group was not diverse from posttest measurement of Mid-calf circumference (cm) $(28.18 \pm 1.89) \mathrm{t} 19=7.236, \mathrm{p}>.05$.

In the same way, significantly the pretest measurement of Mid-Thigh Circumferences $(\mathrm{cm})$ $(50.99 \pm 1.95)$, of control group was not different from the posttest measurement of MidThigh Circumferences $(\mathrm{cm})(50.71 \pm 1.97) \mathrm{t} 19=8.418, \mathrm{p}>.05$. In the same way, significantly the pretest measurement of Mid Arm Circumferences (cm) (29.06 \pm 2.22$)$, of control group was not different from posttest measurement of Mid Arm Circumferences $(\mathrm{cm})(28.77 \pm$ 2.20) $\mathrm{t} 19=9.528, \mathrm{p}>.05$. Similarly, data indicates that significantly pretest measurement of Waist Hip Ratio (.68 \pm .05$)$, of control group was not different from posttest measurement of Waist Hip Ratio $(.68 \pm .058) \mathrm{t} 19=-.972, \mathrm{p}>.05$. In the same way, significantly the pretest measurement of weight $(63.40 \pm 4.23)$, of control group was not different from the posttest measurement of weight $(63.55 \pm 4.24) \mathrm{t} 19=-.900, \mathrm{p}>.05$.

$\mathrm{H}_{\mathrm{A}}$ : There is significant effect of Moderate Intensity Aerobic Exercise on Body Composition of the college girls.

Table 5 Regression showing Impact of Moderated intensity aerobic exercise (MIAE) upon body composition, resting heart rate and Heart Recovery rate

\begin{tabular}{llcccl}
\hline Predictor & Dependent variable & R & R Square & B & Sig. \\
\hline MIAE & Weight & .930 & .866 & .922 & .000 \\
& Fat free mass/lean body mass $(\mathrm{kg})$ & .948 & .898 & .845 & .000 \\
& Fat mass $(\mathrm{kg})$ & .899 & .807 & .652 & .000 \\
& Fat percentage & .864 & .799 & .753 & .000 \\
& Sum of skin fold measurements $(\mathrm{mm})$ & .893 & .825 & .810 & .000 \\
& Mid-calf circumference $(\mathrm{cm})$ & .888 & .810 & .856 & .000 \\
& Mid-Thigh Circumferences $(\mathrm{cm})$ & .762 & .711 & .721 & .000 \\
\hline Mid Arm Circumferences $(\mathrm{cm})$ & .711 & .672 & .771 & .000 \\
\hline
\end{tabular}

Table 5 shows that there is significant impact of Moderate intensity aerobic exercises upon the Weight $(p<.05)$, Fat free mass/lean body mass $(\mathrm{kg})(\mathrm{p}<.05)$, Fat mass $(\mathrm{kg})(\mathrm{p}<.05)$, Fat percentage $(p<.05)$, Sum of skin fold measurement $(\mathrm{mm})(p<.05)$, Mid-calf circumference $(\mathrm{cm})(p<.05)$, Mid-Thigh Circumferences $(\mathrm{cm})(p<.05)$, Mid Arm Circumferences $(\mathrm{cm})(p<$ $.05)$, Waist Hip Ratio $(p<.05)$ and Resting Heart Rate $(p<.05)$ of the girls at college level. The $\mathrm{R}$ square indicates that the effect of Moderate intensity aerobic exercises on Weight $(\mathrm{r} 2=.866$ "87\%"), Fat free mass/lean body mass $(\mathrm{kg})(\mathrm{r} 2=.948$ "95\%"), Fat mass $(\mathrm{kg})(\mathrm{r} 2=$ 
.899 "90\%"), Fat percentage $(r 2=.864$ " $84 \% ")$, Sum of skin fold measurements $(\mathrm{mm})(\mathrm{r} 2=$ .893 "89\%"), Mid-calf circumference $(\mathrm{cm})(\mathrm{r} 2=.888$ "89\%"), Mid-Thigh Circumferences $(\mathrm{cm})$ $(\mathrm{r} 2=.762$ "76\%"), Mid Arm Circumferences $(\mathrm{cm})(\mathrm{r} 2=.711$ "71\%"), Waist Hip Ratio ( $\mathrm{r} 2=.871$ " $87 \%$ ") and Resting Heart Rate ( $\mathrm{r} 2=.911$ "91\%") of the girls at college level. the B indicates that if one unit increase in Moderate Intensity Aerobic Exercises than how many unit increase in dependent variables the unit increased in Weight (.922), Fat free mass/lean body mass $(\mathrm{kg})(.845)$, Fat mass $(\mathrm{kg})(.652)$, Fat percentage (.753), Sum of the skin fold measurements $(\mathrm{mm})(.810)$, Mid-calf circumference $(\mathrm{cm})(.856)$, Mid-Thigh Circumferences (cm) (.721), Mid Arm Circumferences (cm) (.771), Waist Hip Ratio (.842) HA: There is significant impact of Moderate Intensity Aerobic Exercise upon the body composition of the college girls is hereby accepted.

\section{DISCUSSION}

The main purpose of the study was to examine the impact of Moderate Intensity Aerobic Exercises upon Body Composition of College Girls. The determinants of body composition were Weight, Fat free mass/lean body mass, fat mass, fat percentage, Sum of skin fold measurement, Mid-calf circumference, Mid-Thigh Circumference, Mid Arm Circumference, and Waist Hip Ratio. According to Khadijeh et al (2013) composition of the body indicates the fats of the body, weight of the body and thickness of skin. Richard et al (2003) further stated that moderate intensity aerobic exercise is used in a way to make a person healthy and fit plus to achieve the supply the oxygen at good healthy rate to the all-body parts in a way such that heart and blood pressure is not affected in any major way. The two groups were framed out after randomization and odd and even procedure. After the data analysis, the researcher found that there is significant effect of Moderate Intensity Aerobic Exercise upon body composition, resting heart rate and Heart Recovery Rate the results of present study are supported by study of Brandou et al (2003) variety of physical activities such as cycling, walking, jogging and running are advised an effective way for elimination of fats from the body and for the healthy life style.

Halima et al. (2018) argues that cycling is the substitute activity for controlling the obesity. The author Lai et al. (2020) said that walking is also good for aged people to manage their weight The ability to walk is a simplest way to examine the physical function and a vital component for quality life, since it indicates capacity to perform daily activities. Similarly, Asikainen et al. (2003) has observed that collectedly short but rapid walking the day whole can brining to constructive and positive variation in body composition of a person. Brooks (2002) indicated that new modern technological area made life easier, most of the people perform their duties by electronic machinery, and don't involve in any sort of physical activity while the chief sources of gaining fats. In active life style also change the life of the people, walking the key element of the reduction of the extra fats of the body (Matsuzawa et al., 2011). 


\section{CONCLUSION}

The purpose of study was to investigate impact of moderate intensity aerobic exercises upon body composition of college girls. It was found that Eight-week moderate intensity aerobic exercises have significant impact on 9 determinants of body composition were the Weight, Fat free mass/lean body mass, fat mass, fat percentage, Sum of skin fold measurements $(\mathrm{mm})$, the Mid-calf circumference, Mid-Thigh Circumferences, the Mid Arm Circumferences, Waist Hip Ratio. The present study was conducted on the field experiment method further study may be conducted on qasai-experimental method to get more in depth and actual data through labs and filed experiments. It was recommended that the awareness program should be arranged by the concerned authorities to educate the parents, teachers and college girls about the benefit of MIAE in our all promotion of the health.

\section{REFERENCES}

Asikainen, T. M. (2006). Exercise for health for early postmenopausal women. In search of the minimum effective dose among continuous and fractionated walking programs. Tampere University Press.

Asikainen, T. M., Suni, J. H., Pasanen, M. E., Oja, P., Rinne, M. B., Miilunpalo, S. I., ... \& Vuori, I. M. (2006). Effect of brisk walking in 1 or 2 daily bouts and moderate resistance training on lower-extremity muscle strength, balance, and walking performance in women who recently went through menopause: A randomized, controlled trial. Physical Therapy, 86(7), 912-923

Bahamonde, R., Witt, B. S., \& Mikesky, A. (2009). Effects of acute exercise on skinfold measurements. International Journal of Fitness, 5(1).

Ben Halima, N. (Ed.). (2018). Unique Sequence Signatures in Plant Lipolytic Enzymes: Emerging Research and Opportunities: Emerging Research and Opportunities. IGI Global.

Brooks LL. 2002. The effects of after-school physical activity and adult encouragement on adolescents [Research Paper]. Menomonie: University of Wisconsin-Stout

Chen, Y., Ge, W., Parvez, F., Bangalore, S., Ahmed, A., \& Levy, D. (2014). A prospective study of arm circumference and risk of death in Bangladesh. International journal of epidemiology, 43(4), 1187-1196

Clark, M. A., Lucett, S., \& Corn, R. J. (2008). NASM essentials of personal fitness training. Lippincott Williams \& Wilkins

Cook, I., Alberts, M., \& Lambert, E. V. (2008). Relationship between adiposity and pedometer-assessed ambulatory activity in adult, rural African women. International Journal of Obesity, 32(8), 1327

Cook, I., Alberts, M., \& Lambert, E. V. (2008). Relationship between adiposity and pedometer-assessed ambulatory activity in adult, rural African women. International Journal of Obesity, 32(8), 1327 
Nawaz, Luqman \& Khan... The Impact of Moderate

Cornelissen, V. A., Verheyden, B., Aubert, A. E., \&Fagard, R. H. (2010). Effects of aerobic training intensity on resting, exercise and post-exercise, blood pressure heart rate and heart-rate variability. Journal of human hypertension, 24(3), 175-182.

Devang, N. M. (2016). Mid Arm Circumference: An Alternate Anthropometric Index of Obesity in Type 2 Diabetes and Metabolic Syndrome." Journal of Advances in Medicine and Medical Research, 1-8.

Dumortier, M., Brandou, F., Perez-Martin, A., Fedou, C., Mercier, J., \& Brun, J. F. (2003). Low intensity endurance exercise targeted for lipid oxidation improves body composition and insulin sensitivity in patients with the metabolic syndrome. Diabetes \& metabolism, 29(5), 509-518.

Ford, P. A., Perkins, G., \& Swaine, I. (2013). Effects of a 15-week accumulated brisk walking programme on the body composition of primary school children. Journal of sports sciences, 31(2), 114-122.

Gill, J. M., Herd, S. L., \& Hardman, A. E. (2002). Moderate exercise and post-prandial metabolism: issues of dose-response. Journal of sports sciences, 20(12), 961-967

Hardman, A. E. (2001). Physical activity and health: current issues and research needs. International journal of epidemiology, 30(5), 1193-1197.

Hill, J. O., Drougas, H., \& Peters, J. C. (1993). Obesity treatment: can diet composition play a role? Annals of internal medicine, 119(7_Part_2), 694-697.

McTiernan, A., Sorensen, B., Irwin, M. L., Morgan, A., Yasui, Y., Rudolph, R. E., \& Potter, J. D. (2007). Exercise effect on weight and body fat in men and women. Obesity, 15(6), 1496-1512

Moyer, V. A. (2012). Behavioral counseling interventions to promote a healthful diet and physical activity for cardiovascular disease prevention in adults: US preventive Services Task Force recommendation statement. Annals of internal medicine, 157(5), 367-372

Narayani, U., \&Sudhan, P. R. (2010). Effect of aerobic training on percentage of body fat, total cholesterol \& HDL-C among obese women. World Journal of Sport Sciences, 3(1), 33-36

Prabhakaran, B., Dowling, E. A., Branch, J. D., Swain, D. P., \& Leutholtz, B. C. (1999). Effect of 14 weeks of resistance training on lipid profile and body fat percentage in premenopausal women. British journal of sports medicine, 33(3), 190-195

Reid, I. R., Legge, M., Stapleton, J. P., Evans, M. C., \& Grey, A. B. (1995). Regular exercise dissociates fat mass and bone density in premenopausal women. The Journal of Clinical Endocrinology \& Metabolism, 80(6), 1764-1768

Shah, N. R. \& Braverman, E. R. (2012). Measuring adiposity in patients: The utility of body mass index (BMI), percent body fat, and leptin. PLoS One, 7(4).

Sheshadri, A., Kittiskulnam, P., Lai, J. C., \& Johansen, K. L. (2020). Effect of a pedometerbased walking intervention on body composition in patients with ESRD: a randomized controlled trial. BMC nephrology, 21(1), 1-9. 
Stiegler, P., \&Cunliffe, A. (2006). The role of diet and exercise for the maintenance of fatfree mass and resting metabolic rate during weight loss. Sports medicine, 36(3), 239-262.

Swain, D. P., \& Franklin, B. A. (2006). Comparison of cardioprotective benefits of vigorous versus moderate intensity aerobic exercise. The American journal of cardiology, 97(1), 141-147

Turnipseed SD, Richards JR, Kirk JD, Diercks DB, Amsterdam EA. Frequency of acute coronary syndrome in patients presenting to the emergency department with chest pain after methamphetamine use. Journal of Emerging Medicine, 24:369-373.

Williams, C., \& Armstrong, N. (Eds.). (2011). Children and Exercise XXVII. Routledge

Willoughby, D., Hewlings, S., \& Kalman, D. (2018). Body composition changes in weight loss: strategies and supplementation for maintaining lean body mass, a brief review. Nutrients, 10(12), 1876.

Zhang, H., Tong, T. K., Qiu, W., Zhang, X., Zhou, S., Liu, Y., \& He, Y. (2017). Comparable effects of high-intensity interval training and prolonged continuous exercise training on abdominal visceral fat reduction in obese young women. Journal of diabetes research, 2017. 